\title{
SHAPING POLICY FOR THE ASSIGNMENT OF LAND USE
}

\author{
By D. N. OMAND ${ }^{1}$
}

The problem of shaping policy for the assignment of land use is a relatively new one in Canada. The idea that in a country as vast as this, 15 or 20 or 50 million people could not find all the space they need, to do whatever they want to do, appears unlikely on the face of it. The fact that our population is heavily concentrated and is likely to remain so first brought land use problems to the fore, and this has since been complicated by changing patterns of social behaviour, and a transportation revolution which has made the great majority of us virtually as mobile as we wish to be. In any case, land use problems are with us, and will become more complicated as time goes by.

In shaping policy for the assignment of land use, the first and one of the most important problems encountered is that of determining the objectives we wish to aim for. We must predict what products of land use will be in the greatest demand at the time they become available.

The simplest objectives to be determined are the economic objectives, that is, what monetary values may be placed upon the end products of various types of land use. In this field, at least, we have a common yardstick of value with which to measure our products.

For axample Wilson (1) quoted F.A.O. and other figures indicating that world demand for newsprint and pulp and paper products will increase by $59 \%$ by 1975 and lumber demand will increase by about 1/3. This is complicated by present excess capacity, depressed prices and necessity of reducing costs to competitive levels. Nevertheless an increase in demand for these products is likely.

At the same time the current shift in Canadian agriculture from a wheat based industry to a livestock based industry is an indication of present recognition of demand change in this area. Decline in per capita consumption of wheat products in many countries of the world and long term development programs directed toward agricultural self-sufficiency certainly indicate a reduced export demand for what has been the traditional basis of our agricultural economy (2).

These two factors appear to offer an obvious basis in simple terms on which policy for the assignment of land use might be based. The Honourable Alvin Hamilton has used this illustration as a basis for a possible application of the Agricultural Rehabilitation and Development Act (ARDA), that is, the conversion of land resources to the production of commodities for which world demand is increasing, and away from those for which demand is increasing.

\footnotetext{
${ }^{1}$ Supervisor, Wildlife and Enforcement, Ontario Dept. of Lands and Forests, Toronto, Ont.
} 
The United States Department of Agriculture, in its policy guide, sets out the following general objectives for land and water use policy. "The encouragement of land and water uses that will yield continuing maximum benefits to the people of the United States. Those who depend on farming, ranching, and forestry should be helped to assess their needs and find solutions to problems they cannot solve themselves." Policy should assure an abundant and wholesome food supply, adequate sources and supplies of fibre, forest products and industrial raw materials and should assist in the conservation of the land, water, and forest resources. (Conservation in this context is defined as the maintenance and improvement of the productive capacity of the resource) (3).

The determination of economic objectives is much easier now than it used to be. In the past, objectives for land use have been somewhat arbitrary-Carr reported that the legislative-administrative structure directed to land management from 1871 on was designed primarily to promote land settlement and the expansion of farming. The market and drought problems that arose in the 1930's demonstrated that much of the land thus settled was sub-marginal and made the need for more careful planning obvious (4).

In Ontario a long term policy of leasing land in Provincial Parks was abruptly reversed in the mid 50's as the need for public recreational land rose sharply. These are examples of policy changes which might have been avoided if the mechanism for predicting future demand had been more highly developed.

Facilities which are available now for the prediction of world and local demand for the products of land and water, whether these products are tangible or intangible, provide the opportunity to set objectives, and these facilities should be carefully assessed and used critically.

This is of crucial importance. Often the changes made in the land as a result of man-made manipulations are physically irreversible or reversible over a very long period of time, or at great expense. Man has it in his power to make such changes in the face of the earth as to completely alter the biota and indeed the characteristics of the soil and water over large areas. Thousands of years of development of flora and fauna can be wiped out almost overnight, and millions of years of geological development can come to a similar fate. Some of these processes can be reversed, given a few hundred years, and a good deal of money. Nothing can bring back the animals and birds whose habitats have been so drastically altered that the species have disappeared.

If the people responsible for these drastic alterations are vindicated by history, well and good. If they are wrong, their mistakes cannot be rectified. Land manipulation involves an appalling responsibility which I do not believe is always felt by the manipulators.

In the establishment of economic objectives, therefore, provision to match supply with predictable demand for all products of the land is essential. To quote the United States Secretary of Agriculture, "we can balance the productivity of our farm land with the ability of the nation to use food 
and fibre effectively and efficiently by applying more fully our land and water resources in sound conservation programs to meet the growing non farm demands on land and water made by an increasingly urban and metropolitan nation" (5).

It should be noted here that the recreational potential of land and water resources, including camping, hunting, fishing, etc., is considered to be a product of land use which is of great and increasing importance.

The establishment of objectives such as these last that might be described as recreational or social in their significance is a very important element in shaping land use policy.

The products of the recreational use of land are difficult to define, and future demand is difficult to predict. Hills pointed out that the personal nature of recreation and the subjective manner in which it must be experienced make it difficult to define (7). Duncan (8) suggested that new recreational interests are almost impossible to forecast. In spite of this the predictions of population increase, increased leisure and increased mobility, which are so much a feature of many papers and articles on this subject, suggest, on an empirical basis if on no other that demand for space in the outdoors will increase. Surveys conducted by the U.S. Department of the Interior on hunting and fishing practices in 1955 and 1960 indicate that the amount of money spent on these activities increased from 5 billion in 1955 to 7 billion in 1960 (9).

Park campsite registrations in Ontario tripled between 1957 and 1960 (10). The number of statistics of this type that could be cited is great. It is certainly enough to indicate that, barring some major change in leisure habits of our population in general, any comprehensive plan for land use must make a large allowance for substantial recreational use of forest land in the future. How great this allowance must be, and what form it will take, and what facilities will be required is a matter for the individual planner in his own area of responsibility and he knows better than anyone the headaches involved.

Having established objectives which tell us what we want our land and water use policy to produce on the soundest social and economic basis available, several important problems arise in the achievement of these objectives. In the U.S. where about $75 \%$ of the land in the 48 contiguous states is private owned, increasing attention has been directed to multiple use management on this component. In Canada a comparatively small percentage of the land is owned outright by individuals, although a larger percentage of it is in various stages of alienation through timber licenses, pasturage commitments, etc. Thus our land management policy in Ontario and possibly elsewhere in Canada has been heavily weighed toward Crown land. It is interesting to note, however, that greater emphasis on multiple use management of private land has developed in recent years in those areas such as Southwestern Ontario where Crown land is very scarce. 
It is certain that the shapers of policy for the assignment of land use will find two entirely different sets of circumstances on privately owned and publicly owned land.

Although the traditional rights of landowners have been somewhat eroded in the urban or suburban environment by zoning by laws, etc., and in some places even in the rural environment by tree cutting by laws, and taxation policies, in essence property owners continue to exercise the main jurisdiction in the use that is to be made of their land. Thus adjustments in land use policy will continue to be based on enlightened self interest, the creation of an environment where it is to the advantage of the land owner to conform to the policy. The U.S. Department of Agriculture proposed to do this by such things as the purchase of long term easements to discontinue cropping and convert to grassland, cost sharing on capital works required to provide grass and cover, contract growing of trees or outright purchase of private land (6). Obviously this is considered to be no more expensive and more constructive than the continued cost of purchase and storage of farm surpluses.

Under the rather general terms of the ARDA and the draft general agreement which has been set up under the Act, similar programs may now be made available in Canada. Their implementation will depend on how serious the need becomes and how clearly the need can be demonstrated in a political context. Policy can certainly be drafted but to do this without regard for the political realities indicates an optimism which is not common among experienced land managers. It is our tradition that the rights of property owners are sacred, and any changes in the laws governing these rights can be made only after a substantial portion of the population has become convinced that a change is necessary. By this time, the change may be long overdue and its planned effectiveness considerably, reduced. In this field it is difficult to lead public opinion. We should, however, try and at least we should be in the vanguard.

In shaping policy for the assignment of use to publicly owned lands we can take a much more optimistic view. There are many examples of multiple use of lands and waters in Canada. It is true, at least in Ontario, that the land with the greatest potential is in private ownership, and excluding a few fringe areas, the majority of Crown land, due to either climatic, soil or site limitations can have only limited potential. Nevertheless the potentials it does have are those much in demand today and in the foreseeable future. The production of forest products, the provision of recreational environment and crops of fish and game for both consumptive and nonconsumptive use are values for which there is a rapidly increasing demand and policy can be and is being shaped to satisfy this. 
In Ontario there has been increasing acceptance of the multiple use principle of forest operation in recent years. Hills (7) defined multiple use as the condition in which two or more uses of an area are so intimately associated that the areas of each use cannot be separated, or the condition in which the areas devoted to each use can be readily set apart from each other. The most obvious example in my own experience is the use of an area such as Algonquin Park for the production of timber and for recreation. The two interests are consciously and carefully separated by such devices as shoreline cutting limits, care in laying out access roads, restriction of cutting in areas around portages and the retention of wilderness areas but this still leaves a high percentage of the land area of the park which can be managed for timber production without disturbing the recreational foci. In fact, the area that is logged provides what Hills calls the hinterland which gives the foreland much of its recreational value.

Another form of multiple use takes place where managed waterfowl and pheasant hunts take place in parks after the camping season is over. Here, a separation in time rather than in space is used to avoid conflict between the interests. In Michigan a similar arrangement permits the use of public hunting grounds for camping and hiking during the off season. Arrangements of this nature are principally the result of a demonstrated need for all the products of the land, whether tangible or intangible. When the need has been demonstrated and the urgency emphasized, means can be found to produce the necessary policy. Sometimes it involves a drastic change in traditional thinking, and this is often the reason why changes are often overdue before they are made, and why they are not made until pressures develop.

As my colleague Mr. Ward said in his paper on Monday, an attempt to establish additional uses for what has been a single use area is often deemed an invasion by the previous interest, an invasion to be resisted by all possible means. When this happens, only the most obvious demonstration of the urgency of multiple use can be counted upon to reduce the opposition. I do not believe that this is necessarily a bad thing.

It serves as a check on proposals that may be poorly thought out and offers a more complete justification for better land use planning than could otherwise be provided.

In setting up policy for the assignment of land use, then we first require a firm definition of the objectives we wish to attain, the products which we expect the land to yield, whether intangibles, economic or social. Having done this we must demonstrate the urgency of the need for changes in land use policy, demonstrate it in such a way as to overcome the opposition which may be expected.

We are then in a position to balance the interests involved and begin the planning and execution of whatever land manipulation is required to achieve our objectives. 
I see little advantage in listing a series of solutions to land use conflicts which have been reached in the past. There is no rule of thumb, and what works in one situation may not work in a similar context elsewhere because the variables are many, ranging from the land capability to the attitude of the local public.

Disregarding problems of technique then, policy for the assignment of land use that is shaped on the basis of a clear definition of objective, and for which an adequate need has been demonstrated is off to a good start.

\section{REFERENCES}

1. WILSON, D. A. 1961. Demand Prospects for Forest Products - Resources for Tomorrow Background Papers, Volume 2, Page $627-641$.

2. SHIFRIN, F. and MENZIES, M. W. 1961. Demand Outlook for Canadian Agriculture. Resources for Tomorrow Background Papers, Volume 1, Pages $17-31$.

3. U.S.D.A., 1962. Land and Water Resources, A Policy Guide. Pages 3 and 49.

4. CARR, D. W. 1961. Effects of the Legislative and Administrative Framework - Resources for Tomorrow Background Papers, Volume 1, Page 126.

5. FREEMAN, O. L. 1962. Address to the White House Conference on Conservation, Washington, D.C.

6. U.S.D.A., 1962. Op. Cit. Pages 58 and 59.

7. HILLS, G. A. 1961. The Ecological Basis for Land Use Planning. Dept. of Lands and Forests, Ontario, Research Report No. 46.

8. DUNCAN, D. P. 1961. Outdoor Recreational Problems from the Point of View of the Land Manager - Lake States Forest Experiment Station Paper No. 89.

9. National Survey of Hunting and Fishing, 1960. U.S. Department of the Interior Circular 120, Pub. 1961.

10. Ontario, 1961, Annual Report of the Minister of Lands and Forests. 